\title{
OREVER/|
}

\section{Metanálise do Conteúdo Técnico de Diferentes Planos Diretores de Arborização Urbana do Brasil}

\section{Metanalysis of Technical Content of Different Urban Forest Master Plans of Brazil}

\section{Gabriel Mancini Antunes da Silva}

twilight.mancini@hotmail.com

Engenheiro Florestal pela Universidade Federal do Espírito Santo. Mestrando em Engenharia Florestal pela Universidade do Estado de Santa Catarina.

\section{Eleandro José Brun}

eleandrobrun.utfpr@gmail.com

Engenheiro Florestal pela Universidade Federal de Santa Maria. Professor Doutor em Engenharia Florestal na Universidade Tecnológica Federal do Paraná.

\section{Flávia Gizele König Brun}

flaviag@utfpr.edu.br

Engenheira Florestal pela Universidade Federal de Santa Maria. Professora Doutora em Engenharia Florestal na Universidade Tecnológica Federal do Paraná.

\section{Rafael Marian Callegaro}

rafaelm.callegaro@gmail.com

Engenheiro Florestal pela Universidade Federal de Santa Maria. Professor Doutor em Engenharia Florestal na Universidade Federal do Espírito Santo.

\section{Ciro Duarte de Paula Costa}

ciro.floresta@gmail.com

Engenheiro Florestal pela Universidade Tecnológica Federal do Paraná, campus Dois Vizinhos, Paraná.

Recebido em: 12/04/2019

Aprovado em: 25/11/2019
Revista do Programa de Pós-Graduação em Extensão Rural (UFV) 


\title{
OREVER|
}

\section{RESUMO}

O Plano Diretor de Arborização Urbana (PDAU) é um documento que contém o planejamento da arborização urbana de uma determinada localidade, devendo ser elaborado por responsáveis técnicos habilitados, como Engenheiros Florestais, Agrônomos e Biólogos, para evitar que sérios prejuízos ocorram. Este estudo objetivou fornecer subsídios para a elaboração de um Plano Diretor de Arborização Urbana mais completo, com informações detalhadas, usando como ferramenta a comparação entre PDAUs e legislações específicas de diferentes regiões do Brasil, analisando-se variáveis como: os principais profissionais envolvidos na elaboração dos planos e os principais grupos de variáveis empregadas na etapa de inventário florestal urbano em 49 cidades do Brasil. Primeiramente, foram coletados diversos PDAUs disponíveis na internet, através de ferramentas de busca da web, e em bibliografias sobre arborização urbana, de forma separada por estado e em função do porte de cada cidade, segundo o censo populacional mais atual (IBGE, 2010) e Milazzo (2011). Posteriormente, esses dados foram tabelados e foi realizada uma análise em gráficos e planilhas. Como resultado deste trabalho, sugeriu-se a criação de planos modelos para cidades de pequeno, médio e grande porte, servindo como ferramenta de apoio para aquelas que ainda não possuem seus planos. Sugere-se o uso do PDAU de Timóteo (MG) para cidades de pequeno porte, de Palmas (TO) para as de médio porte e do Rio de Janeiro (RJ) para as de grande porte.

Palavras-Chave: PDAUs; Equipe Técnica; Florestas Urbanas; Inventário Arbóreo Urbano.

\begin{abstract}
The Urban Forest Master Plan (UFMP) is a document which contains the planning of the urban trees, which should be prepared by technical responsibles, such as the Forestry Engineers, Agronomists and Biologists, in order to avoid serious damage. This study aimed to provide subsidies for the elaboration of a more complete Urban Forest Master Plan, with detailed information about urban trees, using as a tool the comparison between UFMP's and specific legislation of different regions of Brazil, analyzing variables such as: the main professionals involved in the elaboration of the plans and the main groups of variables used in the urban forest inventory stage of the plans in 49 cities in Brazil. Firstly, several UFMP's available on the Internet were collected through web search tools as well as in bibliographies on urban trees, separately by state and city size, according to the population census (IBGE, 2010) and Milazzo (2011). Subsequently, these data were tabulated and an analysis was made in graphs and spreadsheets. As a result of this work, the creation of model plans was suggested for small, medium and large cities, serving as a support tool for cities that do not yet have their plans. It is suggested to use the UFMP of Timóteo (MG) for small cities, Palmas (TO) for medium-sized cities and Rio de Janeiro (RJ) for large cities.
\end{abstract}

Keywords: UFMP's; Technical Team; Urban Forests; Arboreal Urban Inventory. 


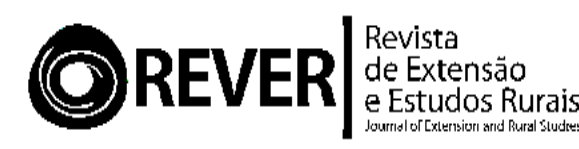

\section{Introdução}

A arborização urbana compreende um conjunto de vegetações arbóreas naturais ou cultivadas que uma cidade apresenta. Atualmente, há uma tendência de a arborização ser reconhecida como um serviço urbano essencial, que influencia diretamente a qualidade de vida de uma população (MORAES; MACHADO, 2014).

A arboricultura urbana pode gerar vários benefícios para a sociedade, como o auxílio na infiltração de água no solo, redução da poluição atmosférica, estabilização de taludes, melhoria para o microclima (reduzindo a temperatura e gerando sombreamento), amenização da velocidade dos ventos, redução da poluição visual e sonora, melhora das condições físicas e psicológicas da população local, além de servir como fonte de alimento para a avifauna (PIRES et al., 2010).

As árvores auxiliam no controle de muitos efeitos adversos do meio urbano, contribuindo para uma significativa melhoria da qualidade de vida. Porém, esses benefícios somente serão obtidos se a arborização urbana for planejada e implantada de maneira adequada (RODOLFO JÚNIOR et al., 2008).

Para um melhor planejamento, é necessário elaborar e implementar o Plano Diretor de Arborização Urbana (PDAU), que indica formas de gestão, planejamento e implantação da arborização urbana, além de conter dados quali-quantitativos da vegetação encontrada nas cidades (MACIEL et al., 2008). Esse documento pode estar presente nas prefeituras, quando a arborização urbana tem abrangência local, e também nos órgãos federais do meio ambiente, quando alcança as esferas local e federal (MACIEL et al., 2008; RANGEL, 2016).

Através do conteúdo abordado pelo PDAU, pretende-se garantir que todas as árvores plantadas tenham condições adequadas para se desenvolverem, evitando que sejam danificadas pela incompatibilidade com as redes aéreas e subterrâneas ou por outros contratempos da infraestrutura urbana (MACIEL et al., 2008). Antes de elaborar e implementar um PDAU, é muito importante fazer uma análise crítica dos planos existentes no Brasil, pois isso auxilia na escolha da metodologia, na tomada de decisões e na definição de diretrizes para novos planos (SANCHES; COSTA; SILVA FILHO, 2008).

Nesse contexto, este trabalho buscou fornecer subsídios para a elaboração de um Plano Diretor de Arborização Urbana mais completo possível, que contenha informações detalhadas, usando como ferramenta a comparação entre PDAUs e legislações específicas de diferentes regiões do Brasil, considerando cidades com diferentes portes segundo o 


\section{OREVER}

IBGE (2010) e Milazzo (2011). Foram identificados os principais profissionais integrantes das equipes que auxiliaram na elaboração dos PDAUs e analisados os principais grupos de variáveis empregadas na etapa de inventário florestal urbano para construção dos planos. Com base nisso, buscou-se recomendar a utilização de PDAUs modelos, indicando os melhores e mais estruturados, de acordo com os diferentes portes de cidade, para servir como material de apoio na elaboração dos planos em várias localidades que ainda não os possuem e também ser uma fonte de dados para futuros trabalhos na área de arborização urbana.

\section{Tópico bibliográfico}

Bargos e Matias (2011) definem que a arborização urbana abrange elementos vegetais arbóreos que estão localizados em meio urbano, como árvores em avenidas, ruas, praças e parques urbanos. Os mesmos autores mencionam que áreas verdes urbanas consistem em um conceito mais amplo, relacionado a indivíduos vegetais encontrados no meio urbano: além de árvores, arbustos e espécies ornamentais, localizadas não só em avenidas, ruas, praças e parques urbanos, mas também em lotes, terrenos baldios e quintais, por exemplo.

Osako et al. (2016) definem os Planos Diretores de Arborização Urbana (PDAUs) como sendo os instrumentos que normatizam todo o planejamento, implantação e manejo das árvores em ambiente urbano (locais públicos).

Crosara (2013) afirma que o Plano Diretor de uma cidade (incluindo a parte de arborização) é tão esquecido pelas autoridades e tão pouco reclamado pelos cidadãos, que acaba tornando-se cada vez mais uma sentença de vida ou morte para o município. É o Plano Diretor que vai direcionar o crescimento urbano, estabelecer critérios de ocupação e ajudar a promover uma das coisas mais inteligentes em uma cidade: sua humanização. Arborizar é humanizar, e havendo esse planejamento é possível promover um certo equilíbrio entre os elementos naturais e artificiais. Quanto maior esse equilíbrio, maiores serão o conforto, a saúde e a qualidade de vida. E, nessa ecologia da cidade, a arborização tem um papel fundamental, promovendo benefícios para a sociedade.

A arborização viária bem planejada pode gerar benefícios como o auxílio na infiltração de água no solo, redução da poluição atmosférica, estabilização de taludes, melhoria para o microclima (reduzindo a temperatura e gerando sombreamento), amenização da velocidade dos ventos, redução da poluição visual e sonora, melhora das 


\section{OREVER P:

condições físicas e psicológicas da população local, além de servir como fonte de alimento para a avifauna (PIRES et al., 2010).

\section{Metodologia}

\section{Coleta das variáveis}

O presente trabalho foi realizado coletando-se diversos PDAUs, de diferentes cidades, disponíveis na internet, através de ferramentas de busca da web. Foram procurados, nessa amostragem, os planos disponíveis em meios digitais de órgãos públicos das esferas municipal, estadual e federal e em bibliografias especializadas da área de arborização urbana. Foram também avaliados tendo em vista os respectivos estados e separados em função do porte das cidades em que foram elaborados e implementados, segundo o censo populacional do IBGE (2010) e Milazzo (2011).

De acordo com o IBGE (2010) e com Milazzo (2011), cidades de pequeno porte são aquelas que possuem menos de 100 mil habitantes, as de médio porte são aquelas que possuem entre 100 mil e 500 mil habitantes, enquanto as de grande porte possuem mais de 500 mil habitantes. Essa classificação serve como base para sugerir PDAUs modelos para as cidades de pequeno, médio e grande porte que ainda não possuem tais documentos.

A metodologia utilizada foi a metanálise, proposta por Lovatto et al. (2007), em que, primeiramente, escolheu-se o objetivo da pesquisa e, posteriormente, foram determinadas as variáveis: portes das cidades (IBGE, 2010 e Milazzo, 2011), os principais profissionais integrantes das equipes que elaboraram os PDAUs, as principais variáveis empregadas na etapa de inventário florestal urbano para construção de planos de arborização e o ano de publicação dos planos. Os dados descritos nessa análise foram retirados dos PDAUs das cidades citadas no Quadro 1, tendo como referencial a estimativa da população no ano de 2018, sendo registrados nessa amostragem: 20 cidades de pequeno porte, 14 de médio porte e 15 de grande porte. 


\section{OREVER e Estudos Rurais}

Quadro 1: Cidades avaliadas com Planos Diretores de Arborização Urbana elaborados e publicados

\begin{tabular}{|c|c|c|c|c|}
\hline Município & Estado & Fonte & $\begin{array}{l}\text { População } \\
\text { (pessoas) }\end{array}$ & Porte \\
\hline Manaus & AM & MANAUS, 2016 & 2.145 .444 & Grande \\
\hline Salvador & BA & SALVADOR, 2017 & 2.857 .329 & Grande \\
\hline Fortaleza & $\mathrm{CE}$ & FORTALEZA, 2015 & 2.643 .247 & Grande \\
\hline Sobral & $\mathrm{CE}$ & SOBRAL, 2018 & 206.644 & Médio \\
\hline Vila Velha & ES & VILA VELHA, 2017 & 486.208 & Médio \\
\hline Vitória & ES & VITÓRIA, 2014 & 358.267 & Médio \\
\hline Goiânia & GO & GOIÂNIA, 2007 & 1.495 .705 & Grande \\
\hline Governador Valadares & MG & GOVERNADOR VALADARES, 2016 & 278.685 & Médio \\
\hline Timóteo & MG & TIMÓTEO, 2016 & 89.090 & Pequeno \\
\hline Campo Grande & MS & CAMPO GRANDE, 2010 & 885.711 & Grande \\
\hline Belém & $\mathrm{PA}$ & BELÉM, 2012 & 1.485 .732 & Grande \\
\hline João Pessoa & PB & JOÃO PESSOA, 2012 & 800.323 & Grande \\
\hline Recife & $\mathrm{PE}$ & RECIFE, 2010 & 1.637 .834 & Grande \\
\hline Andirá & PR & ANDIRÁ, 2016 & 20.139 & Pequeno \\
\hline Bom Sucesso do Sul & PR & BOM SUCESSO DO SUL, 2018 & 3.274 & Pequeno \\
\hline Cascavel & PR & CASCAVEL, 2015 & 324.476 & Médio \\
\hline Ibaiti & PR & IBAITI, 2016 & 31.142 & Pequeno \\
\hline Japurá & PR & JAPURÁ, 2016 & 9.349 & Pequeno \\
\hline Londrina & PR & LONDRINA, 2013 & 563.943 & Grande \\
\hline Maringá & PR & MARINGÁ, 2017 & 417.010 & Médio \\
\hline Pato Branco & PR & PATO BRANCO, 2012 & 81.893 & Pequeno \\
\hline Rolândia & PR & ROLÂNDIA, 2013 & 65.757 & Pequeno \\
\hline Santa Helena & PR & SANTA HELENA, 2016 & 26.206 & Pequeno \\
\hline Telêmaco Borba & PR & TELÊMACO BORBA, 2017 & 78.135 & Pequeno \\
\hline Toledo & $\mathrm{PR}$ & TOLEDO, 2012 & 138.572 & Médio \\
\hline Vitorino & PR & VITORINO, 2017 & 6.817 & Pequeno \\
\hline Porto Velho & RO & PORTO VELHO, 2015 & 519.531 & Grande \\
\hline Macaé & RJ & MACAÉ, 2007 & 251.631 & Médio \\
\hline Rio de Janeiro & RJ & RIO DE JANEIRO, 2015 & 6.688 .927 & Grande \\
\hline Balneário Camboriú & $\mathrm{SC}$ & BALNEÁRIO CAMBORIÚ, 2018 & 138.732 & Médio \\
\hline Aracaju & SE & ARACAJU, 2014 & 648.939 & Grande \\
\hline Araraquara & $\mathrm{SP}$ & ARARAQUARA, 2015 & 233.744 & Médio \\
\hline Bariri & SP & BARIRI, 2006 & 34.961 & Pequeno \\
\hline Capão Bonito & SP & CAPÃO BONITO, 2018 & 47.159 & Pequeno \\
\hline Guararapes & SP & GUARARAPES, 2012 & 32.774 & Pequeno \\
\hline Mirante do Paranapanema & SP & MIRANTE DO PARANAPANEMA, 2017 & 18.178 & Pequeno \\
\hline Olímpia & SP & OLÍMPIA, 2014 & 54.406 & Pequeno \\
\hline $\begin{array}{l}\text { Santo Antônio do } \\
\text { Aracanguá }\end{array}$ & SP & $\begin{array}{l}\text { SANTO ANTÔNIO DO ARACANGUÁ, } \\
2010\end{array}$ & 8.356 & Pequeno \\
\hline São José dos Campos & SP & SÃO JOSÉ DOS CAMPOS, 2016 & 713.943 & Grande \\
\hline Sorocaba & SP & SOROCABA, 2009 & 671.186 & Grande \\
\hline Palmas & TO & PALMAS, 2016 & 291.855 & Médio \\
\hline Erechim & RS & ERECHIM, 2011 & 105.059 & Médio \\
\hline Guaporé & RS & GUAPORÉ, 2009 & 25.475 & Pequeno \\
\hline Ijuí & $\mathrm{RS}$ & IJUÍ, 2011 & 83.173 & Pequeno \\
\hline Palmeira das Missões & $\mathrm{RS}$ & PALMEIRA DAS MISSÕES, 2015 & 33.481 & Pequeno \\
\hline Porto Alegre & RS & PORTO ALEGRE, 2006 & 1.479 .101 & Grande \\
\hline Rio Grande & $\mathrm{RS}$ & RIO GRANDE, 2009 & 210.005 & Médio \\
\hline Santa Cruz do Sul & RS & SANTA CRUZ DO SUL, 2012 & 129.427 & Médio \\
\hline Vacaria & RS & VACARIA, 2013 & 65.846 & Pequeno \\
\hline
\end{tabular}




\section{OREVER}

Os principais profissionais que participaram da elaboração dos PDAUs foram distribuídos nas seguintes categorias: Engenheiros Florestais, Engenheiros Ambientais, Biólogos, Arquitetos, Agrônomos, outros profissionais e profissionais não informados (colaboradores que participaram do planejamento e da elaboração dos planos e não os responsáveis técnicos). Tal variável é importante, pois pode evidenciar se os PDAUs estão sendo elaborados e implementados por profissionais com conhecimento e atribuição técnica legal para trabalhar com arborização urbana e PDAUs - segundo a Lei 5.194/66 e a Resolução 218/73, que definem as atribuições técnicas dos Agrônomos, Engenheiros e Arquitetos, bem como a Lei 6.684/79 e a Resolução 228/10, que definem as atribuições técnicas dos Biólogos e Biomédicos -, além de verificar também a questão da multidisciplinaridade entre as áreas, voltada para elaboração desses planos de arborização.

Nas análises das principais variáveis empregadas na etapa de inventário florestal urbano para construção de PDAUs, foram consideradas as seguintes: nome científico das espécies, coordenadas geográficas, afloramentos radiculares, conflitos urbanos (relacionamentos conflitantes sem ser com fiações elétricas), conflitos com a fiação elétrica, tamanho da área livre, tamanho da calçada, CAP (Circunferência à Altura do Peito) ou DAP (Diâmetro à Altura do Peito), altura total, fitossanidade, altura da primeira bifurcação, podas, manejo e outras categorias.

Utilizando a metodologia proposta por Lovatto et al. (2007), as informações obtidas a partir da bibliografia foram sistematizadas, formando uma base de dados organizada de forma lógica, sem que perdessem a qualidade e os critérios de inclusão.

Em seguida, os dados foram codificados e demonstrados em uma planilha binária, na qual 0 (zero) corresponde a "não" e 1 (um) corresponde a "sim", para os itens avaliados. Após isso, esses dados foram filtrados, para serem utilizadas apenas as informações necessárias na metanálise. Posteriormente, os dados foram analisados através de descrições gráficas e por meio de planilhas.

Os dados foram contabilizados e, em seguida, foram produzidos gráficos utilizando essas variáveis. Para verificar a amplitude entre os dados observados, eles foram divididos em quatro categorias: profissionais participantes, período de elaboração e implantação, principais grupos de variáveis empregadas na etapa de inventário florestal urbano e ano de publicação dos PDAUs. 


\section{OREVER}

\section{Resultados}

Análise dos principais profissionais integrantes das equipes de elaboração e implantação dos PDAUs

Entre os PDAUs avaliados, 27\% contaram com a presença de Engenheiros Florestais como membros da equipe técnica responsável por sua elaboração e implantação, 33\% com Agrônomos, 31\% com Biólogos, 22\% com Arquitetos, 18\% com Engenheiros Ambientais, $27 \%$ com outros profissionais e $47 \%$ não registraram informações acerca dos principais profissionais envolvidos nesse processo (Figura 1).

Figura 1: Principais profissionais integrantes das equipes de elaboração e implantação dos PDAUs nas cidades analisadas

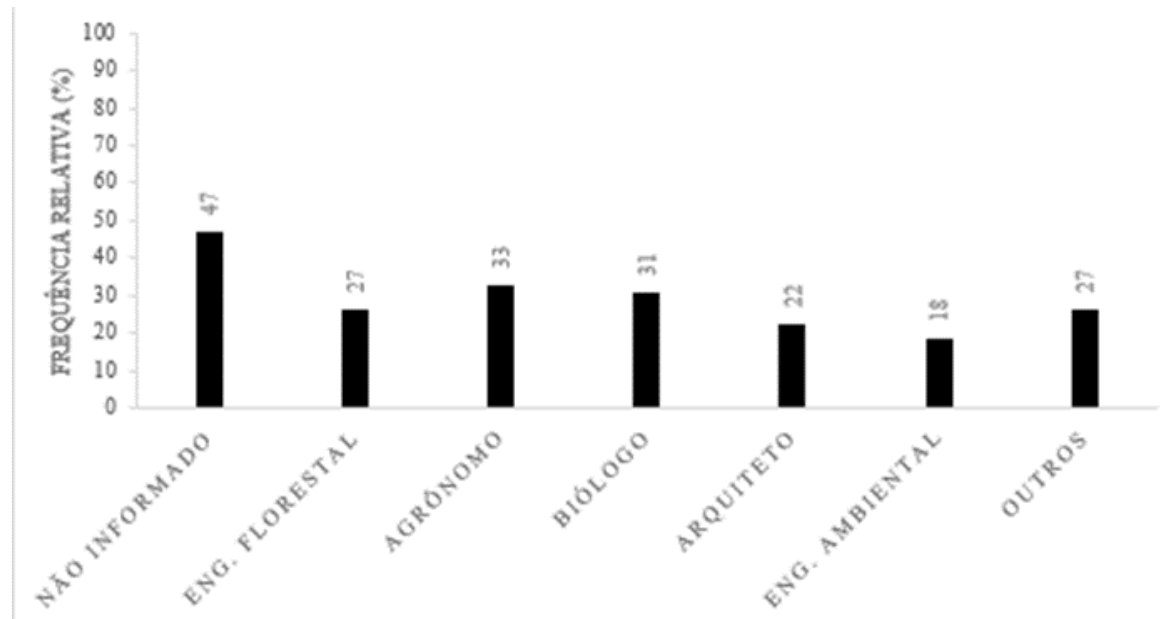

Fonte: Elaborado pelos autores.

Análise dos principais grupos de variáveis empregadas na etapa de inventário florestal urbano para construção de PDAUs

Quanto aos inventários florestais urbanos para construção de PDAUs, verificouse que variáveis referentes ao nome científico das espécies apareceram em $92 \%$ dos PDAUs, a fitossanidade foi avaliada em $86 \%$ dos planos de arborização analisados e o manejo foi informado em 92\%. Porém, as coordenadas geográficas apareceram apenas em 49\% dos PDAUs e a variável referente à altura da primeira bifurcação só aparece em $59 \%$ dos planos (Figura 2). 


\section{OREVER}

Figura 2: Grupos de variáveis empregadas na etapa de inventário florestal urbano para construção de PDAUs

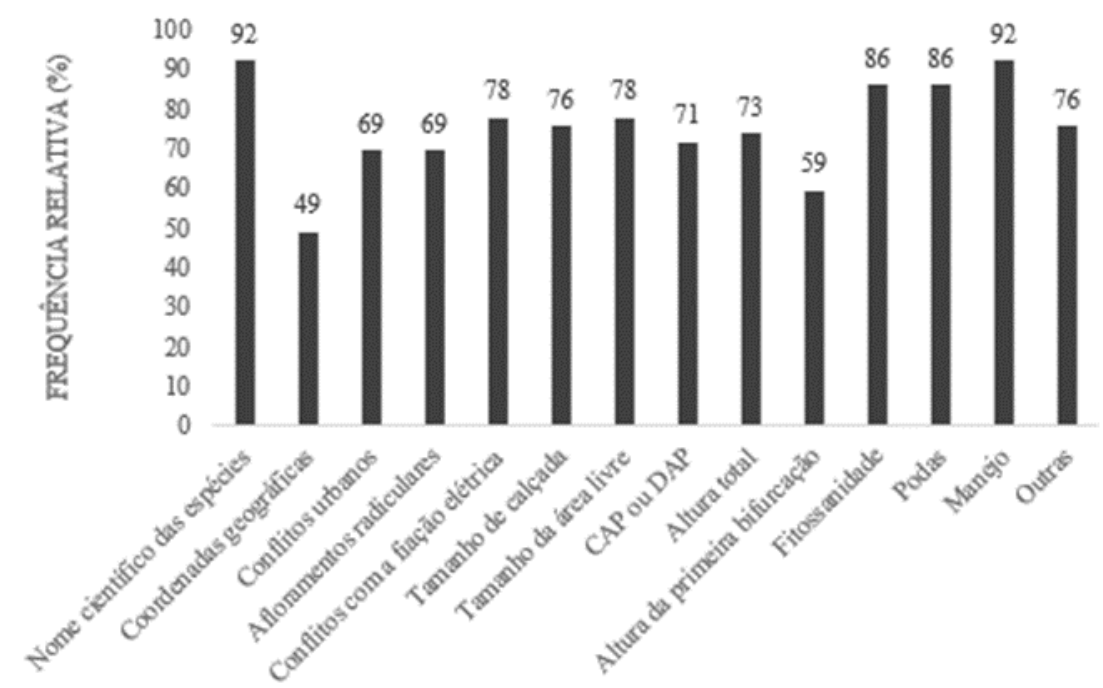

Fonte: Elaborado pelos autores.

\section{Discussão}

\section{Análise dos principais profissionais integrantes das equipes de elaboração e implantação dos PDAUs}

A variedade de profissionais envolvidos na etapa de elaboração dos PDAUs acaba gerando diferentes pontos de vista técnicos, os quais se fazem presentes nos documentos, fato que pode reduzir sua aplicabilidade. Muitos planos de arborização não informam os profissionais envolvidos e suas atribuições técnicas, por serem produzidos de uma maneira muito resumida. Esse fato ocasiona sua não compreensão, de forma adequada, pela população, tendo em vista que também são pouco difundidos ao público. É necessário que os PDAUs sejam corretamente elaborados e divulgados à população, utilizando-se linguagens apropriadas, que facilitem sua compreensão, bem como o acompanhamento da sua implantação.

Quando é analisada a legislação referente às atribuições técnicas, é perfeitamente compreensível que os profissionais mais indicados para gerenciarem planos de arborização urbana sejam os Engenheiros Florestais, devido ao fato de sua formação curricular, realizada ao longo de cinco anos de curso, se basear no estudo de aspectos detalhados e aplicados quanto a ecossistemas florestais e outros associados, bem como na diversidade de espécies (BRASIL, 1966; BRASIL, 1973) e em normativas mais recentes, possuindo grade curricular focada em temas como solos, fitossanidade, 


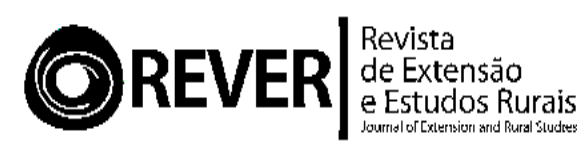

geoprocessamento, fisiologia vegetal, ecologia, silvicultura, dendrologia, dendrometria, inventário florestal, manejo florestal, arborização urbana, entre outros.

Apesar de possuírem uma formação aprofundada no assunto, tais profissionais não participam com maior frequência da execução de serviços voltados à elaboração dos planos, como comprovado nas equipes técnicas responsáveis pelos PDAUs de Rolândia (ROLÂNDIA, 2013), Erechim (ERECHIM, 2011), Toledo (TOLEDO, 2012), Olímpia (OLÍMPIA, 2014) e Guaporé (GUAPORÉ, 2009).

Em segundo lugar, com conhecimento parcialmente ligado ao tema, a partir da análise de sua formação, aparecem os Engenheiros Agrônomos, os quais, apesar de terem entendimento limitado na área que estuda as árvores, possuem melhor instrução quanto a temas referentes a solos, fitossanidade, fisiologia vegetal, entre outros. Em terceiro lugar, aparecem os Biólogos (BRASIL, 1979; BRASIL, 2010), que, apesar de apresentarem conhecimento generalista, possuem boa base de instrução sobre vegetação, mas pouca base quanto a processos de amostragem florestal, geoprocessamento, etc. Em seguida, viriam o Engenheiro Ambiental e o Arquiteto, que possuem bases mínimas de conhecimento sobre vegetação, mas não estudam fertilidade do solo, nutrição de plantas, fitossanidade, etc. Apesar disso, todos os profissionais citados podem contribuir, de alguma forma, em determinados pontos dos PDAUs. Por exemplo, o Engenheiro Ambiental pode participar da produção de mapas, topografia, análise da relação com redes de esgoto e coleta de resíduos sólidos urbanos, o Arquiteto pode atuar no planejamento da paisagem, na adequação da relação com elementos construídos, etc., sendo mais indicado atribuir o gerenciamento dos PDAUs aos Engenheiros Florestais, tendo em vista sua formação específica com conhecimentos diretamente aplicados ao caso.

Mesmo assim, acredita-se que o aspecto mais preocupante nessa questão é a falta de informação sobre o responsável técnico que elaborou o PDAU ou mesmo a sua elaboração por outros profissionais, que não os descritos acima. Ressalvada toda a importância de cada especialista para a sociedade, dentro de sua formação e atuação legal, deve-se ter atenção quanto à formação e à atribuição profissional voltadas para um trabalho de elevada complexidade, como é a elaboração e a execução de um PDAU, o qual não pode ser delegado a leigos no assunto. Os gestores públicos, sob pena de serem acusados de praticarem mau uso dos recursos públicos, devem voltar-se com total atenção para os aspectos relativos às atribuições legais de cada profissional e escolher aquele que está habilitado para a elaboração do PDAU do município. 


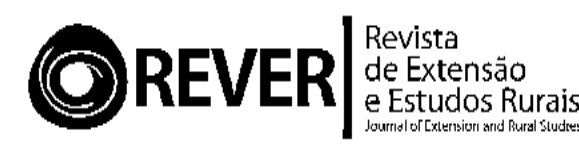

\section{Análise dos principais grupos de variáveis empregadas na etapa de inventário florestal urbano para construção de PDAUs}

Constatou-se a carência de PDAUs mais completos, contendo uma avaliação mais detalhada, com maiores informações e dados, em 50\% das cidades brasileiras avaliadas. Algumas variáveis, referentes às coordenadas geográficas da árvore, de fundamental importância para a construção de mapas de gestão e manejo da arborização, apareceram em apenas $49 \%$ dos PDAUs.

Da mesma forma, a altura da primeira bifurcação, aspecto também fundamental, que visa à não ocorrência de conflitos entre árvores, veículos e pedestres, devendo ser um sinalizador da necessidade de manejo, apareceu em apenas 59\% dos PDAUs.

Tal situação denota o fato de que muitas cidades fazem o inventário florestal urbano de maneira inadequada, por desinteresse ou falta de profissional apto para o trabalho, o qual ocorre mais em função das orientações dos órgãos ligados ao Ministério Público (SANTOS, 2015; CÂMARA MUNICIPAL DE TERESINA, 2013; VITECK, 2015; EDITORIA PALMAS, 2017). Entende-se que a realização de inventários florestais urbanos completos só ocorrerá se houver o trabalho de profissionais com conhecimentos avançados na área, de forma a executar trabalhos técnicos com exigências mais complexas, demandadas pelo meio urbano.

Variáveis como Circunferência à Altura do Peito (CAP) e Diâmetro à Altura do Peito (DAP) estão ausentes em 19\% dos PDAUs avaliados, e a variável referente à altura total foi omitida em 17\% dos planos de arborização analisados. Nesse sentido, em alguns casos, há omissão de dados devido à redução de custos, pois assim, os órgãos públicos podem investir em outras áreas consideradas por eles de maior interesse. Por exemplo, os PDAUs de Recife (RECIFE, 2010) e Aracaju (ARACAJU, 2014) não avaliaram ou não mencionam, em seu inventário, as variáveis CAP ou DAP e altura total, características imprescindíveis para um PDAU, pois remetem à biometria das árvores e servem como critérios básicos para tomada de decisões no manejo da arborização urbana.

Inventários florestais urbanos que não consideram essas variáveis são deficitários por não fornecer embasamento suficiente para a tomada de decisões de profissionais que venham a ser gestores da arborização dessas cidades no presente e no futuro. A economia em recursos públicos ocorrida com a realização de um inventário mais simplificado acaba gerando prejuízos com o atraso e as dificuldades que surgirão na gestão das árvores, por desconhecimento, somente a nível de exemplo, de fatores como a compatibilidade das 


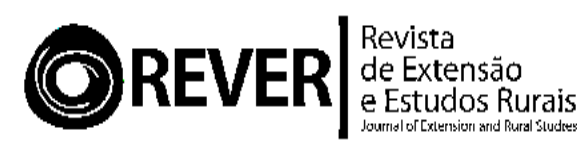

árvores com as áreas livres (em função do CAP ou DAP) e os potenciais conflitos com a fiação aérea (que tem como indicador principal a altura das árvores em comparação à altura da fiação).

Variáveis como nome científico das espécies, conflitos urbanos, afloramentos radiculares, conflitos com a fiação elétrica, tamanho da calçada, tamanho da área livre, fitossanidade, podas e manejos foram avaliadas, no conjunto, em $75 \%$ dos PDAUs analisados, que, por sua vez, demonstraram uma forma mais adequada de inventariar a arborização, como acontece em Palmas (PALMAS, 2016) e em Goiânia (GOIÂNIA, 2007), em detrimento dos outros $25 \%$, que estão inventariando de maneira inadequada ou não divulgando tais procedimentos, como em João Pessoa (JOÃO PESSOA, 2012) e Aracaju (ARACAJU, 2014), sendo necessário avaliar esses dados, para realizar as tomadas de decisões corretas na elaboração e implantação dos planos.

Alguns inventários, como os que deram origem aos PDAUs de Belém (BELÉM, 2012) e de Vitória (VITÓRIA, 2014), não deixam claro se coletaram ou não coordenadas geográficas para o mapeamento das árvores, atividade fundamental para a realização do inventário arbóreo e consecutiva elaboração dos PDAUs, pois os órgãos públicos, em 49\% das cidades avaliadas, podem não ter interesse na área de arborização urbana ou não terem recursos para investir em equipamentos, como o GPS, necessário para a marcação das coordenadas geográficas. A longo prazo, esse tipo de inventário se torna mais aplicável, pois, nas tomadas de decisões ou nas etapas de recoleta de dados, a equipe técnica pode não encontrar os indivíduos arbóreos ou os locais recomendados para plantios ou até mesmo para mapeamentos dessas árvores.

Alguns PDAUs, como os de Goiânia (GOIÂNIA, 2007), Campo Grande (CAMPO GRANDE, 2010) e Palmeira das Missões (PALMEIRA DAS MISSÕES, 2015), contêm mapeamentos, porém não mencionam se há ou não aferição das coordenadas geográficas, relatando apenas os logradouros, os lotes e seus respectivos números, o que não corresponde a uma medida de localização totalmente precisa, pois, em um mesmo ponto da rua, podem haver muitas árvores de determinada espécie, dificultando localizar a árvore desejada. Caso fossem coletadas as coordenadas geográficas, não haveria esse problema, considerando que cada indivíduo possui uma coordenada única, que o diferencia dos demais.

De acordo com Silva et al. (2008), em um inventário quali-quantitativo de arborização urbana, é importante que sejam coletados o nome vulgar e o nome científico das espécies, a altura total, a situação da raiz em relação à calçada, a altura da primeira 


\section{OREVER|}

bifurcação, a área livre do entorno da árvore, as larguras de ruas e calçadas, a fitossanidade, os danos mecânicos, os relacionamentos conflitantes com a infraestrutura urbana e com a fiação elétrica, as podas, a necessidade de manejo e a frequência relativa de cada espécie, pois essas variáveis servem para diagnosticar e subsidiar o planejamento de melhoria da arborização urbana.

Segundo Benatti et al. (2012), as variáveis que devem ser mais utilizadas em um inventário quali-quantitativo de arborização urbana são: marcações de coordenadas geográficas, nome científico das espécies, logradouro em que estas estão localizadas, número do lote próximo às árvores, bairro, data de coleta de registros, lado da fiação elétrica, início e fim da rua, condição da copa, condição do tronco, inclinação da árvore, fitossanidade, influência do sistema radicular arbóreo nas ruas, altura total, altura da primeira bifurcação, CAP, podas, injúrias mecânicas e manejos. Essas variáveis representam uma forma de fornecer subsídios para o planejamento e a manutenção da arborização urbana.

Sendo assim, para gerar os PDAUs, se faz necessária a realização de inventários mais completos, com uso de dados detalhados, a fim de que os planos apresentem a real situação da arborização urbana das cidades onde foram elaborados e implantados. Por isso, é muito importante considerar variáveis como nome científico das espécies, coordenadas geográficas, conflitos urbanos, afloramentos radiculares, conflitos com a fiação, tamanho da calçada, tamanho da área livre, CAP ou DAP, altura total, altura da primeira bifurcação, fitossanidade, podas e, principalmente, manejo da arborização urbana, nesses inventários, para servir como base para tomada de decisões. Outras variáveis, como equilíbrio da copa, integridade do tronco, área de copa, inclinações, tutoramento e injúrias mecânicas, embora ainda sejam pouco visualizadas nos PDAUs, também são muito importantes, pois demonstram o risco de queda das árvores.

Para os Planos Diretores de uma cidade contarem com uma participação popular mais efetiva, há necessidade de atualizar a população com informações sobre a qualidade ambiental, social e de vida, além de considerar critérios de preservação ambiental do ordenamento territorial (PERES; SILVA, 2013; BUENO, 2003). Esse pensamento se reflete nos PDAUs, pois, para que apresentem a real situação da arborização urbana da cidade e sejam divulgados de forma correta para a população, é necessária, além da exposição, a revisão de informações, sendo importante verificar o ano de sua publicação. 


\section{OREVER|}

\section{Considerações finais}

Considerando os objetivos do presente estudo, entre os PDAUs avaliados, muitos apresentaram pendências em relação à presença de profissional qualificado no processo de sua elaboração, destacando-se a ausência de informação quanto ao técnico responsável e à equipe, bem como a existência de planos elaborados por profissional não legalmente habilitado. Esse aspecto é preocupante, na medida em que a sociedade não terá o produto que ela deseja (os benefícios da arborização urbana bem implantada e manejada), mesmo com dispêndio de recursos públicos para tal.

Muitos PDAUs deixam a desejar quanto a sua elaboração, em relação às variáveis analisadas, por não considerarem questões de extrema importância como a localização precisa das árvores (coordenadas obtidas via GPS) ou mesmo a altura de bifurcação. Além disso, uma parcela significativa dos planos (31\%) não avaliou aspectos relativos aos conflitos das árvores com elementos urbanos (placas de trânsito, muros, imóveis, sinais de trânsito, etc.), e 27\% dos planos não apresentaram medidas de CAP ou DAP ou altura das árvores. Os PDAUs sem essas informações contribuirão de maneira infinitamente menor para a gestão e o manejo da arborização das cidades onde forem elaborados.

Além disso, em alguns casos, nem mesmo a correta identificação da árvore através de seu nome científico foi realizada (8\%), não foi avaliada a fitossanidade da árvore $(14 \%)$ e nem o manejo foi feito ou exigido (11\%).

Em termos gerais, sugere-se que esses PDAUs sejam revisados, de forma a se obter a devida complementação das informações necessárias a uma boa gestão e ao manejo da arborização.

Sendo assim, entre os PDAUs avaliados, o modelo a ser indicado para cidades de pequeno porte é o de Timóteo (MG), pois contou com a responsabilidade técnica de um Engenheiro Florestal e também de uma equipe multidisciplinar de profissionais com atribuição técnica para sua elaboração e implantação, além de apresentar parte significativa das variáveis consideradas mais importantes, como DAP, altura total e tamanho das calçadas.

Para cidades de médio porte, recomenda-se o PDAU da cidade de Palmas (TO), pois apresentou extensas e detalhadas avaliações durante o inventário, com medição de CAP, altura total, fitossanidade, conflitos urbanos e conflitos com a fiação. Destaca-se também a ampla divulgação nas mídias locais.

Para cidades de grande porte, recomenda-se como modelo o PDAU da cidade do Rio de Janeiro (RJ), uma vez que possui como responsáveis técnicos Engenheiros 


\section{OREVER|}

Florestais, e que, além de apresentar uma configuração técnica, também foi impresso em formato de cartilhas para que esteja ao alcance de toda a população. Esse plano de arborização foi divulgado em 2015, sendo considerado novo, e segue as legislações pertinentes, gerando resultados positivos para a cidade.

\section{Referências bibliográficas}

ANDIRÁ (cidade). Lei n ${ }^{\circ} 2804$ de 21 de setembro de 2016. Institui o Plano Municipal de Arborização Urbana de Andirá e dá outras providências. Disponível em: <http://andira.pr.gov.br/instances/6/uploads/documents/6233_c16bb05e9ec70f8ffd631e 75675b9ee22b0dd453.pdf $>$. Acesso em: 8 de abr. 2019.

ARACAJU (cidade). Plano municipal de arborização de Aracaju. Aracaju: Prefeitura do município de Aracaju. 2014.

ARARAQUARA (cidade). Decreto $\mathrm{N}^{\circ}$ 10915, de 29 de maio de 2015. Dispõem sobre o Plano de Florestal Urbana do Município de Araraquara - SP, e dá outras providências, $2015 . \quad$ Disponível em: <http://www3.araraquara.sp.gov.br/ImageBank/FCKEditor/file/imprensa01/2015/SECR ETARIAS/MEIO\%20AMBIENTE/10915_29mai15\%20-\%20APROVA\%200\%20PLA NO\%20DE\%20FLORESTA\%20URBANA\%20DO\%20MUNIC\%C3\%8DPIO\%20DE \%20ARARAQUARA.pdf>. Acesso em: 14 de dez. 2018.

BARGOS, D. C.; MATIAS, L. F. Áreas verdes urbanas: um estudo de revisão e proposta conceitual. Revista da Sociedade Brasileira de Arborização Urbana. Piracicaba - SP, v. 6, n. 3, 2011. p. 172-188.

BARIRI (cidade). Plano Diretor de Arborização Urbana do município de Bariri - SP, $2006 . \quad$ Disponível em: 〈https://www.bariri.sp.gov.br/arquivos/27_plano_diretor_de_arborizaCAo_urbana.pdf> . Acesso em: 14 de dez. 2018.

BAUNEÁRIO CAMBORIÚ (cidade). Lei n 4107, de março de 2018. Dispõe sobre as Normas de Arborização Urbana no âmbito do Município de Balneário Camboriú e dá outras providências. Disponível em: <https://leismunicipais.com.br/a/sc/b/balneariocamboriu/lei-ordinaria/2018/410/4107/lei-ordinaria-n-4107-2018-dispoe-sobre-asnormas-de-arborizacao-urbana-no-ambito-do-municipio-de-balneario-camboriu-e-daoutras-providencias>. Acesso em: 14 de dez. 2018.

BELÉM (cidade). Lei no 8909, de 29 de março de 2012. Dispõe sobre o Plano Municipal de Arborização Urbana de Belém - PA, e dá outras providências, 2012. Disponível em: $<$ https://leismunicipais.com.br/a/pa/b/belem/lei-ordinaria/2012/890/8909/lei-ordinarian-8909-2012-dispoe-sobre-o-plano-municipal-de-arborizacao-urbana-de-belem-e-daoutras-providencias>. Acesso em: 31 de mar. 2018.

BENATTI, P. D.; TONELLO, K. C.; ADRIANO JÚNIOR, F. C.; SILVA, J. M. S. da; OLIVEIRA, I. R. de; ROLIM, E. N.; FERRAZ, D. L. Inventário arbóreo-urbano do município de Salto de Pirapora - SP. Revista Árvore. Viçosa - MG, v. 36, n. 5, 2012. p. 


\section{OREVER|}

887-894.

BOM SUCESSO DO SUL (cidade). Plano Municipal de Arborização Urbana de Bom Sucesso do Sul, 2018. Disponível em: $<$ http://www.meioambiente.mppr.mp.br/arquivos/File/Plano_de_Arborizacao_Urbana de_Bom_Sucesso_do_Sul.pdf $>$. Acesso em 8 de abr. 2019.

BRASIL. Lei $n^{\circ}$ 5.194, de 24 de dezembro de 1966. Regula o exercício das profissões de Engenheiro, Arquiteto e Engenheiro-Agrônomo, e dá outras providências. Brasília-DF. Disponível em: 〈http://www.planalto.gov.br/ccivil_03/leis/L5194.htm>. Acesso em: 24 de mai. 2018.

BRASIL. Resolução $n^{\circ}$ 218, de 29 junho de 1973. Discrimina atividades das diferentes modalidades profissionais da Engenharia, Arquitetura e Agronomia. Brasília - DF. Disponível em: $\langle$ http://normativos.confea.org.br/ementas/visualiza.asp?idEmenta=266>. Acesso em: 24 de mai. 2018.

BRASIL. Lei n ${ }^{\circ}$ 6.684, de 3 de setembro de 1979. Regulamenta as profissões de Biólogo e de Biomédico, cria o Conselho Federal e os Conselhos Regionais de Biologia e Biomedicina, e dá outras providências. Brasília - DF. Disponível em: <http://www.planalto.gov.br/ccivil_03/leis/1970-1979/L6684.htm>. Acesso em: 24 de mai. 2018.

BRASIL. Resolução $n^{\circ} 227$, de agosto de 2010. Dispõe sobre a regulamentação das Atividades Profissionais e as Áreas de Atuação do Biólogo, em Meio Ambiente e Biodiversidade, Saúde e, Biotecnologia e Produção, para efeito de fiscalização do exercício profissional. Disponível em: <www.cfbio.gov.br/artigos/RESOLUcaO-No227-DE-18-DE-AGOSTO-DE-2010>. Acesso em: 24 de mai. 2018.

BUENO, L. da S. Zoneamento territorial para fins do uso e ocupação do solo visando a elaboração e atualização de planos diretores. (Tese de doutorado em Engenharia de Produção) - Universidade Federal de Santa Catarina. Florianópolis - SC, 2003. 117 p.

CÂMARA MUNICIPAL DE TERESINA. Antônio Aguiar cobra Plano Diretor de Arborização para Teresina, 2013. Disponível em: <https://www.portalodia.com/noticias/politica/antonio-aguiar-cobra-plano-diretor-dearborizacao-para-teresina-180901.html>. Acesso em: 16 de mai. 2018.

CAMPO GRANDE (cidade). Plano Diretor de Arborização Urbana de Campo Grande MS, 2010. Disponível em: <http://www.campogrande.ms.gov.br/semadur/wpcontent/uploads/sites/24/2017/02/20121029081612.pdf>. Acesso em: 31 de mar. 2018.

CAPÃO BONITO (cidade). Proposta de Plano Municipal de Arborização Urbana do município de Capão Bonito - SP, 2018. Disponível em: <http://www.capaobonito.sp.gov.br/wp-content/uploads/2018/08/P.M.A.U.-CapaoBonito.pdf>. Acesso em: 14 de dez. 2018.

CASCAVEL (cidade). Plano municipal de arborização de Cascavel. Cascavel: Prefeitura do município de Cascavel. 2015. 


\section{OREVER/|}

CAVAlCANTE, M. L. S. A. Administração Pública e Agenda Ambiental - A3P Considerações sobre a implementação nos órgãos públicos. Revista Controle: Doutrina e artigos. Universidade de Fortaleza, Fortaleza - CE, v. 10, n. 1, 2012. p. 196-216.

CRBIO-07. Iniciativa do MP-PR, em parceria com CRBio-07, é tema de Congresso de Arborização em $\quad$ BH, 2016.2 Disponível $<$ http://crbio07.gov.br/midia/noticias/item/148-iniciativa-do-mp-pr,-em-parceria-comcrbio-07,-é-tema-de-congresso-de-arborização-em-bh.html>. Acesso em: 25 de mai. 2018.

CROSARA, R. A percepção da população do bairro Jardim Umuarama sobre a importância de sua arborização. Revista de Estudos Geoeducacionais. Fortaleza - CE, v.4, n.7, 2013. p.16-32.

EDITORIA PALMAS. Sinduscon participa de reuniões sobre Pers-TO e a revisão do Plano Diretor de Palmas, 2017. Disponível em: <https://conexaoto.com.br/2017/02/24/sinduscon-participa-de-reunioes-sobre-o-pers-toe-a-revisao-do-plano-diretor-de-palmas > . Acesso em: 17 de mai. 2018.

ERECHIM (cidade). Plano Diretor de Arborização Urbana do Município de Erechim, RS, 2011. Disponível em: <http://www.pmerechim.rs.gov.br/uploads/files/Plano_Diretor_Arborizacao_Urbana_Er echim_Dez_2011.pdf>. Acesso em: 31 de mar. 2018.

FORTALEZA (cidade). Plano de Arborização de Fortaleza - CE, 2015. Disponível em: $<$ https://urbanismoemeioambiente.fortaleza.ce.gov.br/images/urbanismo-e-meioambiente/infocidade/resultados_plano_de_arborizacao_2015.pdf>. Acesso em: 31 de mar. 2018.

GOIÂNIA (cidade). Plano Diretor de Arborização Urbana de Goiânia - GO, 2007. Disponível em: <http://www.goiania.go.gov.br/download/amma/relatorio_Plano_Diretor.pdf>. Acesso em: 31 de mar. 2018.

GOVERNADOR VALADARES (cidade). Projeto de lei sem número. Dispõe sobre o plano diretor de arborização urbana do município de Governador Valadares - MG, 2016. Disponível

em: <http://www.valadares.mg.gov.br/abrir_arquivo.aspx/Plano_Diretor_de_Arborizacao_U rbana_Do_Municipio_de_Valadares?cdLocal=2\&arquivo=\%7BE14720CA-8A6C-

DCAA-C730-E4EE70A43EBE\%7D.pdf>. Acesso em: 31 de mar. 2018.

GUAPORÉ (cidade). Decreto municipal no. 4189/2009. Institui o Plano Municipal de Arborização Urbana (PMAU) de Guaporé - RS, 2009. Disponível em: <http://www.guapore.rs.gov.br/arquivos/decretos/269.pdf>. Acesso em 31 de mar. 2018.

GUARARAPES (cidade). Plano de Gestão da Arborização Urbana do município de Guararapes $\quad-\quad$ SP, 2012. Disponível em: <https://www.guararapes.sp.gov.br/arquivos/25_plano_de_arborizaCAo_urbana_2012. pdf>. Acesso em: 8 de abr. 2019. 


\section{OREVER|}

IBAITI (cidade). Plano Municipal de Arborização Urbana de Ibaiti - PR, 2016. Disponível em: $<$ http://www.meioambiente.mppr.mp.br/arquivos/File/Plano_de_Arborizacao_Urbana de_Ibaiti.pdf $>$. Acesso em: 8 de abr. 2019.

IBGE. Indicadores Sociais Municipais: uma análise dos resultados do universo do Censo Demográfico, 2010.2 Disponível em: <https://ww2.ibge.gov.br/home/estatistica/populacao/censo2010/indicadores_sociais_m unicipais/indicadores_sociais_municipais_tab_zip.shtm>. Acesso em: 25 de mai. 2018.

IJUÍ (cidade). Lei $\mathrm{n}^{\circ} \mathrm{XX}$. Institui o Plano Diretor de Arborização Urbana do município de Ijuí e dá outras providências, 2011. Disponível em: <http://www.ijui.rs.gov.br/downloads/034b72b546ed06071dbecd7f899bc0146616c12ad c9d4d9d48965d64e33cb492.pdf>. Acesso em: 31 de mar. 2018.

JAPURÁ (cidade). Plano de Arborização Urbana do município de Japurá - PR, 2016. Disponível em: <http://www.japura.pr.gov.br/uploads/legislacao/a2419f9f052ecdb6881e96bf9edb678c. pdf>. Acesso em: 14 de dez. 2018.

JOÃO PESSOA (cidade). Plano de Arborização Urbana de João Pessoa - PB, 2012. Disponível em: <http://www.ligiatavares.com/gerencia/uploads/arquivos/8a7306116dff59e3f908a09b3b 9235f2.pdf>. Acesso em: 8 de abr. 2019.

LONDRINA (cidade). Lei $N^{\circ} 11996$, de 30 de dezembro de 2013. Plano Diretor de Arborização Urbana do município de Londrina - PR, 2013. Disponível em: <http://www1.londrina.pr.gov.br/dados/images/stories/Storage/sec_ambiente/areas_verd es/lei_11996_2013.pdf>. Acesso em: 14 de dez. 2018.

LOVATTO, P. A.; LEHNEN, C. R.; ANDREATTA, L.; CARVALHO, A. D.; HAUSCHILD, L. Meta-análise em pesquisas científicas - enfoque em metodologias. Revista Brasileira de Zootecnia. Viçosa-MG, v. 36, suplemento especial, 2007. p. 285294.

MACAÉ (cidade). Lei n ${ }^{\circ}$ 3010/2007. Disciplina o plantio, o replantio, a poda, a supressão, o transplante e o uso adequado e planejado da arborização urbana, e dá outras providências, 2007. Disponível em: 〈http://www.macae.rj.gov.br/midia/conteudo/arquivos/1421996339.pdf>. Acesso em: 31 de mar. 2018.

MACIEL, J. L.; COGNATO, B. B.; BOFFIL, C. M.; SILVA, M. F. G. da; BORTOLINI, R.; MUHLE, R. P.; LUCHESE, S.; SILVA, K. R. S. da; CARDONE, L. B.; SILVA, G. V. da; GONÇALVES, R. P. B.; CORTEZ, L. S. R. Educação Ambiental como ferramenta para a manutenção da arborização urbana de Porto Alegre - RS. In: Congresso Brasileiro de Arborização Urbana. Anais. Manaus-AM: SBAU, 2008.

MANAUS (cidade). Plano Diretor de Arborização Urbana de Manaus - AM, 2016. Disponível em: <http://semmas.manaus.am.gov.br/wpcontent/uploads/2011/08/Cartilha-Plano-Diretor-de-Arborização-Urbana.pdf>. Acesso 


\section{OREVER|}

em: 31 de mar. 2018.

MARINGÁ (cidade). Projeto de Lei No 14218/2017. Dispõe sobre a elaboração do Plano Diretor de Arborização Urbana município de Maringá - PR, 2017. Disponível: <http://sapl.cmm.pr.gov.br:8080/sapl/sapl_documentos/materia/24006_texto_integral>.

Acesso em: 14 de dez. 2018.

MILAZZO, D. Cidades de porte médio atraem mais imigrantes e crescem mais que capitais, diz IBGE, 2011. Disponível em: <https://noticias.uol.com.br/cotidiano/ultimasnoticias/2011/07/15/cidades-de-porte-medio-atraem-mais-imigrantes-e-crescem-maisque-capitais-diz-ibge.htm>. Acesso em: 25 de mai. 2018.

MIRANTE DO PARANAPANEMA (cidade). Plano Diretor de Arborização Urbana do município do Mirante do Paranapanema - SP, 2017. Disponível em: <https://www.mirantedoparanapanema.sp.gov.br/site/arquivos/arquivos/PLANO\%20MI RANTE.pdf>. Acesso em: 14 de dez. 2018.

MORAES, A. L.; MACHADO, R. R. B. A arborização urbana do município de Timon/MA: inventário da diversidade e diagnóstico quali-quantitativo. Revista da Sociedade Brasileira de Arborização Urbana. Piracicaba - SP, v. 9, n. 4, 2014. p. 80-98.

OLÍMPIA (cidade). Plano Diretor de Arborização Urbana da Estância Turística de Olímpia - $\quad$ SP, $2014 . \quad$ Disponível em: <http://www.daemo.sp.gov.br/documentos/20150925135002.pdf $>$. Acesso em: 31 de mar. 2018.

OSAKO, L. K.; TAKENAKA, E. M. M.; SILVA, P. A. da. Arborização urbana e a importância do planejamento ambiental através de políticas públicas. Revista científica ANAP Brasil. Alta Paulista - SP, v.9, n.14, 2016. p.1-8.

PALMAS (cidade). Plano de Arborização Urbana de Palmas - TO, 2016. Disponível em: <https://docs.wixstatic.com/ugd/6ad4f2_8ec9b66addc64e118f86da7a8db238d6.pdf>.

Acesso em: 31 de mar. 2018.

PALMEIRA DAS MISSÕES (cidade). Lei no 4789 de 28 de abril de 2015. Aprova o Plano Diretor de Arborização Urbana de Palmeira das Missões - RS, 2015. Disponível em: $\quad$ https://leismunicipais.com.br/a1/rs/p/palmeira-das-missoes/leiordinaria/2015/479/4789/lei-ordinaria-n-4789-2015-aprova-o-plano-diretor-dearborizacao-urbana-de-palmeira-das-missoes-rs >. Acesso em: 31 de mar. 2018.

PATO BRANCO (cidade). Lei $\mathrm{n}^{\circ} 3.969$, de 20 de dezembro de 2012. Institui o Plano Municipal de Arborização Urbana do Município de Pato Branco - PR, (PMAU) e dá outras providências. Pato Branco: Prefeitura do município de Pato Branco. 2012.

PERES, R. B.; SILVA, R. S. da. Análise das relações entre o plano de bacia hidrográfica Tietê-Jacaré e os planos diretores municipais de Araraquara, Bauru e São Carlos, SP: avanços e desafios visando a integração de instrumentos de gestão. Revista Sociedade e Natureza. Uberlândia - MG, v. 25, n. 2, 2013. p. 349-362.

PIRES, N. A. M. T. et al. A arborização urbana do município de Goiandira/GO - 


\section{OREVER|}

Caracterização quali-quantitativa e propostas de manejo. Revista da Sociedade Brasileira de Arborização Urbana. Piracicaba - SP, v. 5, n. 3, 2010. p. 185-205.

PORTO ALEGRE (cidade). Resolução COMAM n 05, de 28 de setembro de 2006. Dispõe sobre o Plano Diretor de Arborização Urbana de Porto Alegre - RS, 2006. Disponível em: <http://lproweb.procempa.com.br/pmpa/prefpoa/smam/usu_doc/resolucaoo_5_comam republicacao_final.pdf $>$. Acesso em: 31 de mar. 2018.

PORTO VELHO (cidade). Lei complementar $n^{\circ} 590$, de 23 de dezembro de 2015. Institui o Plano Diretor de Arborização Urbana do município de Porto Velho - RO e da outras providências, 2015.2 Disponível em: <https://sema.portovelho.ro.gov.br/uploads/arquivos/2018/11/27091/1541809810leicomp-n-590-de-2312-15-institui-o-plano-diretor-de-arborizacao-urbana-1.pdf>. Acesso em: 8 de abr. 2019.

RANGEL, T. L. V. Comentários à Proteção das Áreas Verdes Urbanas: Influxos da Edificação do Meio Ambiente Urbano Sustentável. Conteúdo jurídico, Brasília-DF: 24 de jul. 2015. Disponível em: <http://www.conteudojuridico.com.br/?artigos\&ver=2.54105\&seo=1>. Acesso em: 08 abr. 2019.

RECIFE (cidade). Plano de Arborização da cidade do Recife - PE, 2010. Disponível em: 〈http://www2.recife.pe.gov.br/wp-content/uploads/CADERNO_PLANO.pdf>. Acesso em: 31 de mar. 2018.

RIO DE JANEIRO (cidade). Plano Diretor de Arborização Urbana do Rio de Janeiro RJ, 2015.2 Disponível em: <http://www.rio.rj.gov.br/dlstatic/10112/5560381/4146113/PDAUtotal5.pdf>. Acesso em: 31 de mar. 2018.

RIO GRANDE (cidade). Lei $\mathrm{n}^{\circ}$ 6832, de 31 dezembro de 2009. Dispõe sobre o Plano Diretor de Arborização Urbana do município de Rio Grande - RS, 2009. Disponível em: $<$ http://www.riogrande.rs.gov.br/pagina/arquivos/lei/lei_6.832_-

_plano_diretor_de_arborizacao.pdf>. Acesso em: 31 de mar. 2018.

RODOLFO JÚNIOR, F.; MELO, R. R. de; CUNHA, T. A. da; STANGERLIN, D. M. Análise da arborização urbana em bairros da cidade de Pombal no estado da Paraíba. Revista da Sociedade Brasileira de Arborização Urbana. Piracicaba - SP, v.3, n.4, 2008. p.3-19.

ROLÂNDIA (cidade). PMAU - Plano Municipal de Arborização Urbana de Rolândia PR, 2013. Disponível em: <http://www.rolandia.pr.gov.br/images/stories/Meioambiente/PLANO\%20MUNICIPAL\%20DE\%20ARBORIZA\%C3\%87\%C3\%830\%20 URBANA-ROL\%C3\%82NDIA.pdf>. Acesso em>14 de dez. 2018.

SALVADOR (cidade). Lei n ${ }^{\circ}$ 9187/2017. Dispõe sobre o Plano Diretor de Arborização Urbana do Município de Salvador - BA, 2017. Disponível em: <https://leismunicipais.com.br/a/ba/s/salvador/lei-ordinaria/2017/919/9187/leiordinaria-n-9187-2017-dispoe-sobre-o-plano-diretor-de-arborizacao-urbana-do- 


\section{OREVER|}

municipio-de-salvador>. Acesso em: 31 de mar. 2018.

SANCHES, P. M.; COSTA, J. A.; SILVA FILHO, D. F. da. Análise comparativa dos planos diretores de arborização enquanto instrumento de planejamento e gestão. Revista da Sociedade Brasileira de Arborização Urbana. Piracicaba - SP, v. 3, n. 4, 2008. p. 5374.

SANTA CRUZ DO SUL (cidade). Lei no 6447, de 04 de janeiro de 2012. Estabelece normas de manejo, proteção, conservação das formações vegetais, arborização e procedimentos para supressão, transplante ou podas de espécimes vegetais no município de Santa Cruz do Sul, institui o Plano Diretor de Arborização, e dá outras providências, 2012. Disponível em: <https://leismunicipais.com.br/a/rs/s/santa-cruz-do-sul/leiordinaria/2012/644/6447/lei-ordinaria-n-6447-2012-estabelece-normas-de-manejoprotecao-conservacao-das-formacoes-vegetais-arborizacao-e-procedimentos-parasupressao-transplante-ou-podas-de-especimes-vegetais-no-municipio-de-santa-cruz-dosul-institui-o-plano-diretor-de-arborizacao-e-da-outras-providencias >. Acesso em: 31 de mar. 2018.

SANTA HELENA (cidade). Plano Municipal de Arborização Urbana de Santa Helena PR, PMAUSH, 2016. Disponível em: $<$ http://www.santahelena.pr.gov.br/uploads/arquivos/conselho_meioambiente/PLANO MUNICIPAL_DE_ARBORIZACAO_URBANA_2016.pdf>. Acesso em: $14 \mathrm{de} \mathrm{dez}$. 2018.

SANTO ANTÔNIO DO ARACANGUÁ (cidade). Plano de Arborização de Santo Antônio do Aracanguá - SP, 2010. Disponível em: $<$ https://pt.scribd.com/document/205984285/Plano-de-Arborizacao-Urbana-SantoAntonio-do-Aracangua >. Acesso em: 31 de mar. 2018.

SANTOS, C. Promotoria cobra plano de arborização em Cornélio, Leópolis e Sertaneja, 2015. Disponível em: <http://www.revelia.com.br/posts/detalhe/17136>. Acesso em: 16 de mai. 2018.

SÃO JOSÉ DOS CAMPOS (cidade). Sistematização de informações sobre Arborização Urbana de São José dos Campos - SP, 2016. Disponível em: <http://servicos.sjc.sp.gov.br/downloads/elat667.pdf>. Acesso em: 8 de abr. 2019.

SILVA, B. P da; FREIRE, G. Caracterização da arborização urbana da região central do município de Tefé-AM. (Trabalho de Conclusão de Curso em licenciatura em Ciências Biológicas) - Universidade do Estado do Amazonas. Tefé - AM, 2014. 16p.

SILVA, L. M. et al. Inventário da arborização urbana em duas vias de Mariópolis/PR. Revista da Sociedade Brasileira de Arborização Urbana. Piracicaba - SP, v.3, n.1, 2008. p.36-53.

SOBRAL (cidade). Plano de Arborização Urbana do município de Sobral - CE, 2018. Disponível em: <http://www.sobral.ce.gov.br/media/com_download/files/20180824142826.pdf>.

Acesso em: 14 de dez. 2018. 


\section{OREVER|}

SOROCABA (cidade). Plano de Arborização Urbana de Sorocaba - SP, 2009. Disponível em: $<$ http://meioambiente.sorocaba.sp.gov.br/educacaoambiental/wpcontent/uploads/sites/3/2015/11/plano-de-arborizaco-urbana-de-sorocaba-20092021.pdf >. Acesso em 31 de mar. 2018.

TELÊMACO BORBA (cidade). Plano de Arborização Urbana de Telêmaco Borba - PR, 2017. Disponível em: <http://www.telemacoborba.pr.gov.br/images/planodiretor/P7.2\%20PLANO\%20DE\%2 0ARBORIZAÇAO\%20URBANA\%20-\%20PROPOSTAS\%20-\%20PRELIMINAR.pdf >. Acesso em: 31 de mar. 2018.

TIMÓTEO (cidade). Plano Municipal Integrado de Arborização Urbana de Timóteo MG, 2016.2 Disponível em: <http://www.timoteo.mg.gov.br/adminsite/arquivos/Imprensa/DownloadsDiversos/A00 10170.pdf>. Acesso em: 31 de mar. 2018.

TOLEDO (cidade). Plano Diretor de Arborização Urbana (PDAU) de Toledo - PR, 2012. Disponível em: 〈http://www.toledo.pr.gov.br/sites/default/files/planodearborizacaotoledo.pdf $>$. Acesso em: 31 de mar. 2018.

VACARIA (cidade). XX COMDEMA $n^{\circ} \mathrm{XX}$, de XX de XX de 2013. Dispõe sobre o Plano Diretor de Arborização Urbana de Vacaria - RS, 2013. Disponível em: <http://www.vacaria.rs.gov.br/docs/PLANODEARBORIZACAO-Versao-

Preliminar.pdf>. Acesso: 31 de mar. 2018.

VILA VELHA (cidade). Lei $\mathrm{n}^{\circ}$ 5.873, de 06 de julho de 2017. Autoriza o poder executivo municipal a instituir o plano diretor municipal de arborização urbana de Vila Velha - ES, PDMAUVV, condições para o manejo, a proteção e conservação da arborização e dá outras providências, $2017 . \quad$ Disponível em: <http://www.vilavelha.es.gov.br/legislacao/Arquivo/Documents/legislacao/html/L5873 2017.html>. Acesso em: 31 de mar. 2018.

VITECK, C. M. Pedralli cobra criação dos planos cicloviário e de arborização urbana em Marechal Rondon, 2015.2 Disponível em: <http://www.marechalcandidorondon.pr.leg.br/institucional/noticias/pedralli-cobracriacao-dos-planos-cicloviario-e-de-arborizacao-urbana-em-marechal-rondon>. Acesso em: 17 de mai. 2018.

VITÓRIA (cidade). Lei no 8696, de 29 de julho de 2014. Dispõe sobre o uso e a gestão da arborização urbana e das áreas verdes de uso público, do município de Vitória - ES, e dá outras providências, 2014. Disponível em: <http://www.cmv.es.gov.br/Arquivo/Documents/legislacao/html/L86962014.html>. Acesso em: 31 de mar. 2018.

VITORINO (cidade). Plano Municipal de Arborização Urbana de Vitorino - PR, 2017. Disponível em: $<$ http://www.meioambiente.mppr.mp.br/arquivos/File/Plano_de_Arborizacao_Urbana de Vitorino.pdf>. Acesso em: 8 de abr. 2019. 